\title{
Efeito da oscilação de temperatura e umidade do ar no comportamento de Salmonella Enteritidis em ovos de galinha contaminados*
}

\author{
Effect of oscillation of temperature and air humidity in the behavior \\ of Salmonella Enteritidis in contaminated chicken eggs
}

\author{
Karen Apellanis Borges ${ }^{1}$, Andrea Troller Pinto ${ }^{2} \&$ Edir Nepomuceno da Silva ${ }^{3}$
}

\begin{abstract}
RESUMO
A salmonelose humana é uma doença de ocorrência mundial, sendo Salmonella Enteritidis o sorovar mais isolado. A doença está associada ao consumo de produtos de origem animal, sendo que o ovo é considerado um dos principais transmissores. Muitos fatores podem influenciar na manutenção da bactéria na superfície e sua penetração no conteúdo interno, entre eles a qualidade da casca, a temperatura e a umidade do ar. Recomenda-se a refrigeração em todas as fases de processamento na cadeia produtiva de ovos, mas no Brasil não há exigência nem fiscalização para controle deste procedimento, podendo ocorrer quebra da cadeia de frio, submetendo os ovos a oscilações de temperatura e umidade. Muitos estudos utilizam métodos que favorecem o processo de contaminação dos ovos, mas não mimetizam as formas naturais de contaminação. Este trabalho teve como objetivo simular oscilações de temperatura e umidade durante o processamento de ovos in natura com casca contaminada artificialmente, e verificar a importância da qualidade da casca e dessas oscilações na manutenção do agente na superfície e sua consequente penetração no conteúdo. Nesse estudo utilizaram-se ovos de galinha com casca íntegra e casca defeituosa, artificialmente contaminados com fezes, contendo Salmonella Enteritidis. Submeteu-se esses ovos a armazenamento com oscilações de temperatura e umidade e fez-se a contagem bacteriana da superfície do ovo e do conteúdo interno (albúmen e gema). Verificou-se que a viabilidade de micro-organismos na superfície do ovo foi menor quando esses foram submetidos à temperatura de $30^{\circ} \mathrm{C}$, independentemente da qualidade da casca, analisando até o final do período de análise. Observou-se uma maior tendência de invasão da bactéria em ovos de casca defeituosa quando expostos a $30^{\circ} \mathrm{C}$.
\end{abstract}

Descritores: ovos in natura, qualidade da casca.

\section{ABSTRACT}

The human salmonellosis is a disease that occurs all around the world. Salmonella Enteritidis is the most isolated serovar. This disease is associated with the consumption of animal products. Eggs are considered one of the main responsible products. Many factors can influence in the maintenance of the bacteria on the surface and its penetration into the internal content, including shell's quality, temperature and air moisture. It is recommended refrigeration at all stages of processing in the production chain of eggs, but in Brazil there is no requirement or supervision to control this procedure, which can occur fall of the cold chain, subjecting the eggs to fluctuations in temperature and moisture. Many studies use methods that force the contamination process of eggs, but does not mimic the natural forms of contamination. This study simulated swings in temperature and moisture during the processing of artificially contaminated shells, and verify the importance of shell's quality in the maintenance of the agent on the surface and its consequent penetration of the content. In this study it was used eggs from hens that were artificially contaminated with feces containing Salmonella Enteritidis. These eggs were submitted to storage with fluctuations in temperature and moisture. After, a counting of the bacteria was done on the surface of the egg and the internal content (albumen and yolk). It was found that the viability of microorganisms on the surface of the egg was lower when these were storage to temperatures of $30^{\circ} \mathrm{C}$ regardless of the quality of the shell, looking toward the end of the reporting period. There was a greater tendency for invasion of bacteria in shell eggs for defective when exposed to $30^{\circ} \mathrm{C}$.

Keywords: egg in nature, shell quality.

* Trabalho originado da tese de doutorado do segundo autor. Programa de Pós-graduação em Tecnologia de Alimentos, Faculdade de Engenharia de Alimentos, UNICAMP, Campinas/SP. 'Programa de Pós-graduação em Ciências Veterinárias, Universidade Federal do Rio Grande do Sul (UFRGS), Porto Alegre, RS. ${ }^{2}$ Faculdade de Medicina Veterinária, UFRGS. ${ }^{3}$ Biocamp Laboratório LTDA - Campinas/SP. CORRESPONDÊNCIA: A .T. Pinto [andrea.troller@ufrgs.br; Fone: (51) 33089999 - Fax: +55 (51) 33087305$].$ 


\section{INTRODUÇÃO}

Salmonella é uma causa comum de infecções alimentares em humanos, sendo transmitida através da ingestão de alimentos contaminados por fezes de animais infectados [1]. O sorotipo mais prevalente é Salmonella Enteritidis [8]. Muitas pesquisas incriminam o ovo como principal transmissor $[3,6,7,9,11]$, mas estudos demonstram que apenas uma pequena parcela deles contém a bactéria no interior ou na superfície [15].

Os principais fatores que influenciam a penetração da bactéria no ovo são número de poros e qualidade da casca, $\mathrm{pH}$, pressão de vapores, temperatura e umidade relativa do ar $[5,11,13,14,18]$. A temperatura de armazenagem é fator limitante da multiplicação de agentes na superfície do ovo, e a deficiência de resfriamento e o excesso de umidade podem predispor à penetração da mesma no interior do ovo [5]. Os riscos de contaminação aumentam quando a casca apresenta-se defeituosa, porosa, fina ou rachada [17].

Para prevenir ou reduzir a multiplicação destes organismos na casca, recomenda-se refrigeração dos ovos, mas, no Brasil, não existem leis que exijam resfriamento destes. Também não é feito controle do tempo entre produção e consumo, sendo esse um ponto crítico da cadeia produtiva.

Muitos estudos utilizam métodos que favorecem o processo de contaminação dos ovos [14], mas essas metodologias não mimetizam as formas usuais de contaminação, impossibilitando a quantificação adequada da disseminação do agente [19].

O objetivo do trabalho foi simular as oscilações de temperatura e umidade relativa do ar que acontecem durante o processo de transporte e armazenagem do ovo de consumo, a fim de se verificar o comportamento do micro-organismo de uma maneira eficaz.

\section{MATERIAIS E MÉTODOS}

Foram utilizados ovos brancos de galinha, oriundos de poedeiras com idade entre 24 e 64 semanas de idade, da linhagem HySex White. Esses ovos foram selecionados no laboratório conforme a qualidade da casca, por ovoscopia e gravidade específica pelo método de flutuação. O método de flutuação baseia-se no uso de soluções salinas com diferentes densidades, na qual os ovos são imersos sucessivamente nessas soluções, da solução de menor densidade até a de maior densidade, sendo a gravidade específica dada pela densidade da solução onde o ovo flutuou primeiro, considerando ovos com maior qualidade da casca aqueles com maior gravidade específica [16]. Entre os ovos selecionados, descartaram-se aqueles que possuíam peso inferior a $60 \mathrm{~g}$, tolerando-se uma variação de $\pm 3 \mathrm{~g}$. Os ovos foram separados em dois grupos: com e sem defeitos de casca, sendo considerados defeituosos aqueles que apresentaram casca fina, porosa ou com pequenas rachaduras sem rompimento das membranas internas. Após a classificação, os ovos foram incubados a $42^{\circ} \mathrm{C}$ de 6 a 8 horas, visando a simular a temperatura no momento da postura.

Foi utilizada uma cepa de Salmonella Enteritidis fagotipo 4 (SE FT4), isolada da produção avícola. Essas cepas foram marcadas através de mutação em

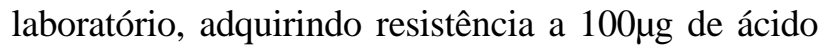
nalidíxico por mililitro de meio de cultura, a fim de facilitar a recuperação e a contagem das mesmas nos materiais analisados.

A cultura de SE foi inoculada em TSB com $100 \mu \mathrm{g} / \mathrm{mL}$ de acido nalidíxico (NAL) e $100 \mu \mathrm{g} / \mathrm{mL}$ de novobiocina (NOB) por 24 horas a $35^{\circ} \mathrm{C}$, transferindo-se alíquotas de $1 \mathrm{~mL}$ para $100 \mathrm{~mL}$ de TSB NAL/ NOB, incubando-se a $35^{\circ} \mathrm{C}$ por 20 a 24 horas. $\mathrm{O}$ antimicrobiano novobiocina foi utilizado pelo mesmo motivo do ácido nalidíxico, aproveitando-se a resistência natural do micro-organismo. Após a incubação, o caldo foi centrifugado $(4.000 \mathrm{rpm}, 15$ minutos a $25^{\circ} \mathrm{C}$ ), desprezando-se o sobrenadante e adicionandose $5 \mathrm{~mL}$ de água peptonada tamponada ao precipitado de células. Após esse procedimento, obteve-se o inóculo utilizado para a contaminação das fezes.

Para esse experimento, foram utilizadas fezes de galinha oriundas do mesmo lote doador de ovos. Essas fezes foram esterilizadas por calor úmido e posteriormente contaminadas com a cepa bacteriana. As fezes foram contaminadas de forma a obter-se contaminação média de $10^{7}$ Unidades Formadoras de Colônia (UFC) por grama de fezes.

Os ovos foram contaminados através de leve pressão desses sobre as fezes, em apenas uma das faces, na região equatorial, sem rotação, durante 10 minutos. Após, os ovos foram colocados em bandejas plásticas limpas e sanitizadas e deixados em câmara de fluxo laminar para secagem à temperatura ambiente, de 60 a 75 minutos, para só depois serem armazenados nas condições do estudo. Foram contaminados 45 ovos com casca íntegra e 45 ovos com casca defeituosa, sendo amostrados de cada um dos grupos, 30 unidades. 
A armazenagem se deu em regime de temperatura $\mathrm{X}$ umidade, sendo que do tempo zero até a $24^{\mathrm{a}}$ hora de armazenagem, os ovos foram mantidos a $8^{\circ} \mathrm{C}$ e $70+5 \%$ UR; da $24^{\mathrm{a}}$ até a $72^{\mathrm{a}}$ hora a $30^{\circ} \mathrm{C}$ e $90+5 \%$ UR; e da $72^{\mathrm{a}}$ hora até o final do experimento $\left(336^{\mathrm{a}}\right.$ hora) a $8^{\circ} \mathrm{C}$ e $70+5 \%$ UR. Foram coletados cinco ovos em cada etapa de análise, sendo que essas foram realizadas nos tempos $0,24,48,72,168$ e 336 horas de armazenamento. Ao final do ensaio, as unidades não utilizadas foram descartadas após esterilização.

Para a recuperação do micro-organismo da casca, realizou-se a lavagem do ovo [10]. Primeiramente, foi feito o acondicionamento dos ovos em sacos plásticos estéreis, procedeu-se à lavagem com $5 \mathrm{~mL}$ de água peptonada tamponada aquecida a $35-38^{\circ} \mathrm{C}$, esfregando-se as cascas por 60 segundos. A água da lavagem foi armazenada em tubos de vidro estéreis, para que fossem feitas as diluições seriadas em água peptonada $0,1 \%$. Após, foi feita inoculação em superfície de Agar MacConkey NAL/NOB. Quando se esperava uma contagem muito baixa, fez-se o plaqueamento de $1 \mathrm{~mL}$ de água de lavagem distribuído em quatro placas de Agar MacConkey. A água de lavagem foi incubada a $35-37^{\circ} \mathrm{C}$, por 24 horas, para verificar a presença ou a ausência dos microorganismos, caso não se obtivesse a contagem.

Para a contagem em albúmen e gema, procedeu-se à desinfecção dos ovos com imersão total destes em álcool $70^{\circ} \mathrm{GL}$ por 40 minutos, em seguida sofreram secagem à temperatura ambiente em câmara de fluxo laminar. Os ovos foram assepticamente manipulados na extremidade mais obtusa, pipetando-se o albúmen e transferindo-o para um saco plástico es- téril, enquanto que as gemas e as chalazas foram transferidas para o separador de clara e gema, e secas com gaze estéril, para se retirar resíduos de albúmen. A gema foi arma-zenada em um saco plástico estéril. Os sacos contendo gema e albúmen foram pesados e o conteúdo diluído em água peptonada tamponada para diluição $10^{-1}$. Após, foi feita inoculação em superfície de Agar MacConkey de cada uma das amostras, com poste-rior incubação de 24 a 48 horas e contagem bacteriana das placas. As amostras diluídas foram incubadas a $35-37^{\circ} \mathrm{C}$, por 24 horas, para verificar a presença ou a ausência dos micro-organismos, caso não se obtivesse a contagem.

Os dados de contagem bacteriana na casca sofreram análise de variância e, havendo diferença significativa entre as condições de armazenamento, foi realizado o teste de Tukey para verificar as diferenças $(\alpha=0,05)$. Os dados gerados a partir da contagem de micro-organismos no albúmen e na gema dos ovos foram analisados pelo teste de Fischer.

\section{RESULTADOS}

A Tabela 1 apresenta o comportamento de Salmonella Enteritidis, em relação à contagem e à sobrevivência, na casca de ovos íntegros e defeituosos contaminados artificialmente por fezes, ao longo do tempo. Encontrou-se a bactéria na superfície de todos os ovos durante todo o período experimental, independentemente das condições ambientais e da qualidade da casca. Não houve diferença significativa no comportamento do micro-organismo na superfície de ovos com casca íntegra ou defeituosa $(\alpha$ de 0,05$)$.

Tabela 1. Contagem de Salmonella Enteritidis na superfície de ovos com casca íntegra ou defeituosa contaminados via fezes e armazenados em regime de oscilação de temperatura e umidade relativa

\begin{tabular}{cccccc}
\hline $\begin{array}{c}\text { Condição de } \\
\text { armazenagem }\end{array}$ & $\begin{array}{c}\text { Tempo de } \\
\text { armazenagem }\end{array}$ & \multicolumn{2}{c}{ Ovos com casca íntegra } & \multicolumn{2}{c}{ Ovos com casca defeituosa } \\
& $N / n$ & Média & $N / n$ & Média \\
\hline $8^{\circ} \mathrm{C}$ e 70\% UR & 0 horas & $5 / 5$ & $1,24 \times 10^{3}$ & $5 / 5$ & $1,24 \times 10^{3}$ \\
$30^{\circ} \mathrm{C}$ e 90\% UR & 24 horas & $5 / 5$ & $6,66 \times 10^{3}$ & $5 / 5$ & $1,18 \times 10^{3}$ \\
$30^{\circ} \mathrm{C}$ e 90\% UR & 48 horas & $5 / 5$ & $1,14 \times 10^{4}$ & $5 / 5$ & $4,19 \times 10^{4}$ \\
$8^{\circ} \mathrm{C}$ e 70\% UR & 72 horas & $5 / 5$ & $1,09 \times 10^{5}$ & $5 / 5$ & $3,93 \times 10^{4}$ \\
$8^{\circ} \mathrm{C}$ e 70\% UR & 168 horas & $5 / 5$ & $2,34 \times 10^{4}$ & $5 / 5$ & $3,68 \times 10^{4}$ \\
$8^{\circ} \mathrm{C}$ e 70\% UR & 336 horas & $5 / 5$ & $1,56 \times 10^{5}$ & $5 / 5$ & $1,08 \times 10^{5}$ \\
& Média: & $30 / 30$ & $5,13 \times 10^{4}$ & $30 / 30$ & $3,45 \times 10^{4}$ \\
\hline
\end{tabular}

$\mathrm{N} / \mathrm{n}$ : Unidades amostrais com crescimento/total de amostras analisadas. Média: UFC por unidade de casca 
Na Tabela 2, estão apresentados os resultados referentes à penetração do agente no conteúdo interno dos ovos de galinha com casca íntegra e defeituosa ao longo do tempo. $\mathrm{Na} 48^{\mathrm{a}}$ hora de armazenagem (ou seja, 24 horas de armazenamento a $30^{\circ} \mathrm{C}$ ), duas unidades amostrais com casca defeituosa apresentaram contaminação de gema e albúmen, enquanto que apenas uma unidade dos ovos íntegros apresentou contaminação do interior, sendo esta apenas no albúmen. $\mathrm{O}$ crescimento de micro-organismo nessa unidade amostral de casca íntegra só foi possível após enriquecimento em água peptonada tamponada a $35^{\circ} \mathrm{C}$ por 24 horas. Estes achados mostram a tendência de invasão por SE no conteúdo de ovos, entretanto a qualidade da casca não afetou significativamente $(\alpha$ de 0,05$)$ este comportamento.

\section{DISCUSSÃO}

A presença da bactéria na superfície de ovos com casca íntegra ou defeituosa ao longo de todo o expe-rimento deve-se à existência de matéria orgânica e condições que permitiram a manutenção da umidade superficial. Essas condições também permitiram que, ao longo do tempo, ocorresse a multiplicação do agente.

Em outro estudo [11], foi demonstrado que ovos armazenados em temperaturas mais baixas apresentam maior viabilidade de Salmonella Enteritidis ao longo tempo do que aqueles mantidos em temperaturas mais altas. Neste mesmo estudo, concluiu-se que a umidade do ar não foi importante, mas as oscilações de temperatura poderiam ocasionar a conden-sação da umidade na superfície externa do ovo, favo-recendo a entrada de Salmonella. Apesar de não haver diferença significativa, no presente estudo é possível observar que só foi encontrado o micro-organismo no conteúdo dos ovos após eles terem sido submetidos a condensação de umidade.

Os ovos com casca defeituosa apresentaram um maior número de células bacterianas no conteúdo interno, visto que apenas nestes foi possível realizar a contagem bacteriana, enquanto que em ovos com casca de boa qualidade, foi possível apenas a detecção da presença do micro-organismo. Nos ovos de casca íntegra, apenas foi possível observar a presença de Salmonella Enteritidis, o que sugere uma quantidade menor de micro-organismos. Caso estes ovos, mesmo íntegros, sejam utilizados com outros ingredientes ou com mais ovos na preparação de um alimento, pode haver a multiplicação do agente, elevando a possibilidade de provocar uma infecção humana.

Em um estudo no qual foi feita a simulação da condensação de umidade na superfície de ovos, concluiu-se que a qualidade da casca parecia ser mais importante do que a presença de umidade [2]. Porém, utilizou-se uma metodologia de imersão dos ovos amostrais em caldo de cultura contendo Salmonella Enteritidis, o que poderia ter superestimado a real contaminação de albúmen e gema. Já nesse estudo, a tendência de um maior número de ovos com casca defeituosa ser invadida pelos micro-organismos indica que,

Tabela 2. Contagem de Salmonella Enteritidis em albúmen e gema de ovos com casca íntegra ou defeituosa, contaminados via fezes e submetidos a regime de oscilação de temperatura e umidade relativa

\begin{tabular}{|c|c|c|c|c|c|c|c|}
\hline \multirow{3}{*}{$\begin{array}{c}\text { Condição de } \\
\text { armazenagem }\end{array}$} & \multirow{3}{*}{$\begin{array}{c}\text { Tempo de } \\
\text { armazenagem }\end{array}$} & \multicolumn{2}{|c|}{$\begin{array}{c}\text { Ovos com casca } \\
\text { íntegra }\end{array}$} & \multicolumn{4}{|c|}{ Ovos com casca defeituosa } \\
\hline & & \multirow{2}{*}{$\begin{array}{c}\text { Albúmen } \\
\qquad N / n\end{array}$} & \multirow{2}{*}{$\begin{array}{c}\text { Gema } \\
N / m\end{array}$} & \multicolumn{2}{|c|}{ Albúmen } & \multicolumn{2}{|c|}{ Gema } \\
\hline & & & & $N / n$ & Média & $N / n$ & Média \\
\hline $8^{\circ} \mathrm{C}$ e $70 \%$ UR & 0 horas & n.r. & n.r. & n.r. & - & n.r. & - \\
\hline $30^{\circ} \mathrm{C}$ e $90 \%$ UR & 24 horas & $0 / 5$ & $0 / 5$ & $0 / 5$ & - & $0 / 5$ & - \\
\hline $30^{\circ} \mathrm{C}$ e $90 \%$ UR & 48 horas & $1 / 5$ & $0 / 5$ & $2 / 5$ & $4,02 \times 10^{5}$ & $2 / 5$ & $4,19 \times 10^{4}$ \\
\hline $8^{\circ} \mathrm{C}$ e $70 \%$ UR & 72 horas & $0 / 5$ & $0 / 5$ & $0 / 5$ & - & $0 / 5$ & - \\
\hline $8^{\circ} \mathrm{C}$ e $70 \%$ UR & 168 horas & $0 / 5$ & $0 / 5$ & $0 / 5$ & - & $0 / 5$ & - \\
\hline \multirow[t]{2}{*}{$8^{\circ} \mathrm{C}$ e $70 \%$ UR } & 336 horas & $0 / 5$ & $0 / 5$ & $0 / 5$ & - & $0 / 5$ & - \\
\hline & Média: & $1 / 25$ & $0 / 25$ & $2 / 25$ & & $2 / 25$ & \\
\hline
\end{tabular}

N/n: Unidades amostrais com crescimento/total de amostras analisadas. Média: UFC por mL/grama de amostra. n.r.: não realizado 
mesmo quando existe contaminação localizada na superfície das amostras, pode haver um maior risco de penetração da bactéria no conteúdo, caso os ovos sejam submetidos à condensação de umidade.

\section{CONCLUSÕES}

Este estudo tentou simular as condições de transporte e armazenamento aos quais os ovos são submetidos durante sua cadeia de produção. Verificou-se que a qualidade da casca não interfere significativamente na viabilidade de Salmonella Enteritids na superfície da casca de ovos de galinhas, enquanto que a oscilação de temperatura durante a armaze-nagem favorece a manutenção da viabilidade do micro-organismo na superfície da casca, sendo mais importante quando as temperaturas são mais baixas. Esse resultado demons-tra a importância que o controle de temperatura e umidade durante o beneficiamento, associado às práticas higiênicas, para evitar a contaminação, possui, para evitar que os ovos apresentem uma grande quantidade de micro-organismos ao chegarem até o consumidor. A associação dos fatores qualidade de casca e oscilação de temperatura predispõe a invasão bacteriana do conteúdo. Uma vez que os ovos apresentam contaminação na superfície da casca, as oscilações de temperatura durante o transporte e armazenagem podem permitir uma maior penetração de Salmonella Enteritidis no conteúdo interno. Essas oscilações de temperatura podem ser representadas, na prática, pela ausência de refrigeração durante o transporte e pela oscilação de temperatura, como a armazenagem de ovos na porta da geladeira do consumidor. Isso indica que deve haver um controle de temperatura desde a coleta dos ovos na granja até o final da cadeia produtiva, no uso que o consumidor final fará deles.

Agradecimentos. Agradecimento à Coordenação de Aperfeiçoamento de Pessoal de Nível Superior (CAPES), órgão financiador da bolsa de estudo do segundo autor, e à Fundação de Amparo a Pesquisa do Estado de São Paulo (FAPESP), órgão financiador da pesquisa.

\section{REFERÊNCIAS}

1 Berchieri Jr. A. 2000. Salmoneloses Aviárias. In: Berchieri Jr. A. (Ed). Doença das Aves. Campinas: FACTA, pp.185-196.

2 Ernst R.A., Fuqua L., Riemann H.P. \& Himathongkhan S. 1998. Effect of sweating on shell penetration of Salmonella enteritidis. Journal Applied Poultry Science. 7: 81-84.

3 Gama N.M.S.Q., Berchieri Jr. A. \& Fernandes S.A. 2003. Occurrence of Salmonella sp. in laying hens. Brazilian Journal of Poultry Science. 5: 15-21.

4 Gast R. \& Beard C.W. 1992. Detection and enumeration of Salmonella Enteritidis in fresh and stored eggs laid by experimentally infected hens. Journal Food Protection. 55: 152-156.

5 Graves R.C. \& Maclaury D.W. 1962. The effect of temperature, vapor pressure, and absolute humidity on bacterial contamination of shell eggs. Poultry Science. 41: 1219-1225.

6 Humphrey T.J. 1994. Contamination of egg's shell and contents with Salmonella Enteritids: a review. International Journal Food Microbiology. 21: 31-40.

7 Mayes F.J. \& Takeballi M.A. 1983. Microbial contamination of the hen's eggs: a review. Journal Food Protection. 46: 1092-1098.

8 Nascimento V.P. \& Santos L.R. 2005. Salmonella Enteritidis: implicações em saúde pública e na qualidade dos produtos avícolas. In: Anais do V Simpósio de Sanidade Avícola da UFSM. (Brasil, Santa Maria). P.122.

9 Peresi J.T.M.,Almeida I.A.Z.C., Lima S.I., Marques D.F., Rodrigues E.C.A., Fernandes S.A., Gelli D.S. \& Irino K. 1998. Surtos de enfermidades transmitidas por alimentos causados por Salmonella Enteritidis. Revista de Saúde Pública. 32: 477-483.

10 Pinto A.T. 2005. Estudo do comportamento de Salmonella Enteritidis e Escherichia coli na casca, sua penetração no conteúdo interno e alterações na qualidade em ovos de galinha contaminados artificialmente simulando condições usuais de produção comercial. 164f. Campinas, SP. Tese (Doutorado em Tecnologia de Alimentos) - Faculdade de Engenharia de Alimentos, Universidade Estadual de Campinas.

11 Radkowski M. 2002. Effect of moisture and temperature on survival of Salmonella Enteritidis on shell eggs. Archiv für Geflügelkunde. 66: 119-123.

12 Rodrigue D.C., Tauxe R.V. \& Rowe B. 1990. International increase in Salmonella enteritidis: a new pandemic? Epidemiology and Infection. 105: 21-27. 
13 Sauter E.A. \& Petersen C.F. 1974. The effect of egg shell quality on penetration by various Salmonellae. Poultry Science. 53: 2159-2162.

14 Sauter E.A., Peterson C.F. \& Parkinson J.F. \& Steele E.E. 1979. Effect of pH on egg shell penetration by salmonellae. Poultry Science. 56: 1754-1755.

15 Summers J. 2004. How much do eggs contribute to the Salmonella problem. Poultry Industry Council. 1: 1. [Fonte: $<$ http://www.poultryindustrycouncil.ca>].

16 Thompson B.K. \& Hamilton R.M.G. 1982. Comparision of the precision and accuracy of the flotation and Archimedes' methods for measuring the specific gravity of eggs. Poultry Science. 61: 1599-1605.

17 Tood E.C.D. 1996. Risk assessment of use of cracked eggs in Canada. International Journal Food Microbiology. 30: 125143.

18 Walden C.C., Allen I.V.F. \& Trussell P.C. 1956. The role of the egg shell and shell membranes in restraining the enter of microorganisms. Poultry Science. 35: 1190-1196.

19 World Health Organization. 2002. Risk assessments of Salmonella in eggs and broiler chickens: interpretative summary. (WHO - Microbiological Risk Assessment Series, 2). 302p. 